\title{
Viremia en plasma como factor asociado a gravedad en la infección por el virus del dengue: revisión sistemática de la literatura
}

\author{
Sergio Alejandro Gómez Ochoa
}

Universidad Industrial de Santander, Bucaramanga, Santander, Colombia. Facultad de Salud Escuela de Medicina. Investigador Grupo GERMINA-UIS

El autor declara no tener conflicto de interés en la realización de este artículo.

La realización del presente trabajo no requirió financiamiento.

Recibido (segunda versión): 16 de octubre de 2017 Aceptado: 5 de abril de 2018

Correspondencia a: Sergio Alejandro Gómez Ochoa sagomezo.182@gmail.com

\author{
Plasma viraemia as a factor associated to severity in dengue virus infection: \\ systematic review of literature
}

Background: Plasma viremia is a factor whose role in the severity of dengue virus infection has been widely discussed in recent years, with divergent results found in the multiple contexts evaluated. Methods: A systematic review of the literature using the Scopus, EBSCOhost, SpringerLink, Lilacs and Scielo databases was conducted. For inclusion in the review there were considered studies that evaluated the relationship between plasma viral load and clinical manifestations or severity of the disease. Results: We obtained 80 references in the initial search, after the application of the inclusion / exclusion criteria 20 articles were selected. In the study of this phenomenon there are multiple parameters from which viremia should be evaluated, not only from its magnitude, but also from the post-defervescence duration and the day in which the maximum value is reported, among others. Discussion: The results of the studies indicate that the characteristics of viremia may play an important role that, along with other factors of the viral (virus serotype, type of infection) and patient context (age, genotype, comorbidities, etc.), determine the clinical outcome of the infection.

Key words: dengue virus, viremia, severe dengue.

Palabras clave: virus del dengue, viremia, dengue grave.

\section{Introducción}

$\mathrm{E}$ 1 dengue es en la actualidad la arbovirosis más importante a nivel global. Esta enfermedad es causada por los cuatro serotipos del virus del dengue y transmitida a los seres humanos por los vectores Aedes aegypti y Aedes albopictus, especies con una amplia distribución mundial, principalmente entre las latitudes $35 \mathrm{~N}$ y $35 \mathrm{~S}^{1-3}$. Según la Organización Mundial de la Salud, se estima que esta entidad provoca de 50 a 100 millones de casos de enfermedad al año en el mundo ${ }^{4}$, siendo el continente americano una de las regiones más afectadas, con un incremento alarmante en el número de casos en los últimos años con posterioridad al fracaso del programa de erradicación de A. aegypti a finales de la década de $1970^{5}$. Los países del continente con mayor actividad del virus en las últimas décadas han sido, en primer lugar Brasil, seguido de Colombia, Cuba, Ecuador, Perú y Venezuela, mientras que sólo dos, Uruguay y Chile continental, han permanecido sin transmisión indígena del virus ${ }^{6,7}$.

En Colombia, el dengue se considera una entidad endemo-epidémica en regiones por debajo de los 1.800 metros sobre el nivel del mar, lo que lleva a que una importante proporción de la población se encuentre en riesgo ${ }^{8}$. Para el año 2015 se reportaron 94.916 casos de dengue en el país, de los cuales $1,4 \%$ correspondió a dengue grave (DG). Por su parte, el Departamento de Santander reportó 8,8\% del total, ubicándose tercero en la lista de departamentos con más casos de esta enfermedad'.

A pesar de que la mayoría de infecciones por el virus del dengue resultan en una enfermedad febril auto-limitada, conocida como la forma clásica o dengue clásico (DC), su presentación clínica es variable, pudiendo manifestarse en formas más graves como el dengue hemorrágico o el síndrome de choque por dengue, escenarios caracterizados por defectos en la hemostasia y fuga de plasma ${ }^{10}$. Esta condición de DG a menudo resulta fatal de no manejarse la fuga de líquido plasmático de manera oportuna por lo que el diagnóstico adecuado de esta entidad se convierte en una prioridad en el contexto actual, en el que otras infecciones virales transmitidas por mosquitos adquieren una importancia cada vez mayor ${ }^{11,12}$.

Sin embargo, el diagnóstico convencional de infección por el virus del dengue resulta insuficiente para determinar si el paciente presentará una forma grave de la enferme$\operatorname{dad}^{13,14}$. Derivado de esta dificultad, múltiples estudios han evaluado marcadores de gravedad con el propósito de determinar qué pacientes tienen mayor probabilidad de padecer esta condición. Dentro de los factores asociados a gravedad de la enfermedad se han relacionado la 
primoinfección por el serotipo 3 del virus ${ }^{15}$, la actividad de distintos tipos de HLA (A-03, A-24, A-33, B-57) ${ }^{16-18}$, las infecciones secundarias por otro serotipo distinto al causante de la primoinfección ${ }^{15}$, niveles elevados de biomarcadores séricos como las citoquinas (ST2, TRAIL, FNT $\alpha$, IL-1beta, IFN-gamma, IL-4, IL-6, IL-13, IL-7 y GM-CSF) ${ }^{19-21}$, viremia prolongada ${ }^{22}$, niveles elevados de antígeno NS1 en sangre ${ }^{23}$ y una carga viral en sangre elevada ${ }^{24-29}$, entre otros. Con respecto a este último, su asociación con las formas graves de la enfermedad no ha sido completamente aceptada, pues existen estudios en los que no se ha hallado una relación directa entre la carga viral en sangre y el desarrollo de $\mathrm{DG}^{30-35}$. Por ende, la discusión sobre este factor y su mecanismo fisiopatológico en el dengue continúa abierta. A esto se debe agregar que hasta la fecha en la literatura científica no existe publicación alguna que recopile los resultados de los estudios realizados en esta área.

Dado el contexto y la plausibilidad biológica de que la viremia sea un factor influyente en la gravedad de la enfermedad se considera necesaria la realización de la presente revisión, la que tiene el propósito de brindar una visión global y actualizada acerca de los hallazgos publicados con respecto a la relación entre la viremia del dengue y la presentación clínica de sus formas graves, tema controvertido, pero de gran importancia para el estudio del fenómeno del DG.

\section{Metodología}

\section{Criterios de elegibilidad}

Se consideraron para su inclusión en la revisión estudios que evaluaran la relación entre la carga viral en plasma (representada como el número de copias de ARN viral $/ \mathrm{mL}$ ) y las manifestaciones clínicas y la gravedad de la enfermedad en pacientes con diagnóstico confirmado de dengue.

Por otra parte, fueron descartados para su selección los estudios que evaluaran formas graves del dengue sin incluir factores asociados, estudios que describieran factores relacionados a gravedad en dengue sin incluir la carga viral, investigaciones realizadas en modelos animales, artículos de revisión y finalmente aquellos escritos en otro idioma distinto al inglés, español o portugués.

\section{Estrategia de búsqueda}

Se realizó una búsqueda de la literatura científica utilizando las bases de datos Scopus, EBSCOhost, SpringerLink, Lilacs y Scielo en el tiempo comprendido entre el 27 de junio y el 24 de julio de 2016, utilizando los siguientes términos (líneas) de búsqueda: dengue virus AND viremia AND severity como primera línea, dengue virus AND viral load AND severity como segunda y dengue virus AND viral burden AND severity como tercera línea.

\section{Evaluación y recolección de los estudios}

Se realizó una revisión general de los resultados de la búsqueda inicial, evaluando cada publicación por su título y seleccionando aquellas que mostraran una relación directa o indirecta con el objetivo del estudio. Posteriormente, se efectuó una revisión individual de los resúmenes, seleccionando los que cumplían los criterios de inclusión y exclusión definidos. Finalmente, las listas de referencias de los artículos evaluados fueron valoradas manualmente para la inclusión de otros estudios pertinentes no encontrados en la búsqueda.

\section{Resultados}

La revisión de la literatura científica identificó 80 artículos aptos para ser incluidos en el manuscrito, siendo 35, 33 y 12 resultados de cada línea de búsqueda, respectivamente. Se aplicó un filtro manual a partir de la revisión de los resúmenes encontrando que 58 referencias no ofrecían información útil relacionada al objetivo principal del estudio.

A posteriori se procedió a descargar los artículos para su evaluación completa, siendo descartados dos en esta fase por cumplir otros criterios de exclusión (Figura 1). Finalmente fueron seleccionadas 20 referencias (Tabla 1) de las cuales se descargó los artículos para su revisión completa. Los estudios incluidos fueron publicados entre los años 1981 y 2016; éstos evaluaron el impacto que tienen las características de la viremia (magnitud, valores pico, duración y valores post-defervescencia) en las manifestaciones de la enfermedad, específicamente aquellas relacionadas con el DG.

El número total de pacientes incluidos fue de 2.642, con un predominio del género masculino (54\%) y una edad promedio de 26 años ( $\mathrm{DE} \pm 5,9)$, siendo siete estudios realizados en población pediátrica (edad promedio 7,7 años; DE $\pm 2,2)^{24,25,29,30,33,35,36}$.

Las investigaciones fueron realizadas en países endémicos, principalmente de Asia (75\%) -específicamente del Sudeste asiático (65\%) - y el continente americano (20\%). Asimismo, la mayoría de la población evaluada provino de países asiáticos (71\%). Del total, fueron evaluados 830 casos (31\%) de DG, 1.082 casos (41\%) de DC y 405 (15\%) de dengue con signos de alarma (DSA) o de una forma intermedia del mismo, definida como una elevación del hematocrito entre $15-20 \%$, evidencia de efusión pleural menor a $1 \mathrm{~mm}$ en la radiografía de tórax en decúbito lateral o recuento plaquetario mayor de $100.000 / \mathrm{mm}^{3}$ a pesar de cumplir criterios para fuga de plasma. Finalmente, en $13 \%$ de los individuos no fue disponible la información de esta condición ${ }^{24}$. 


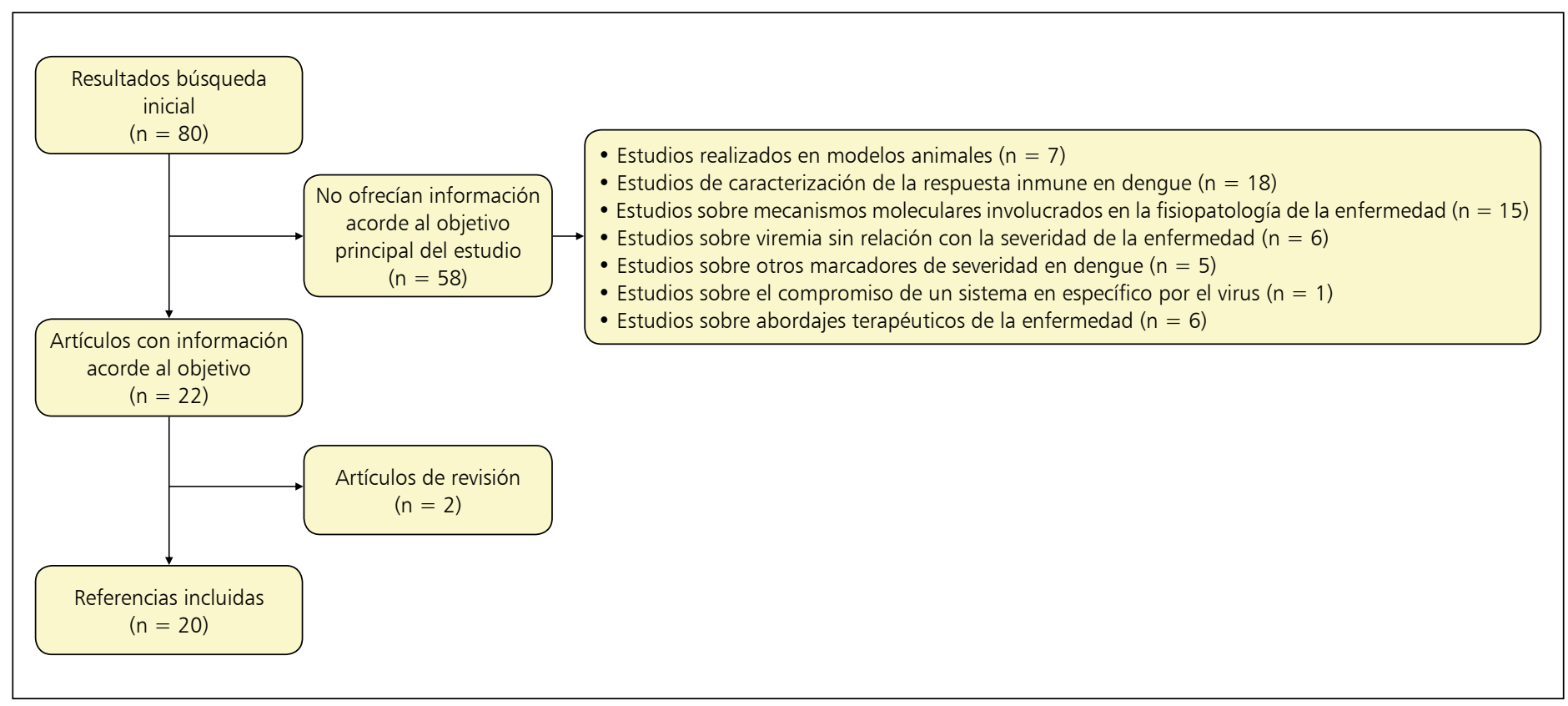

Figura 1. Proceso de selección de los estudios.

Tabla 1. Descripción general de los artículos incluidos en la revisión

\begin{tabular}{|c|c|c|c|c|}
\hline Autores & País & $\begin{array}{l}\text { Tamaño de } \\
\text { muestra }\end{array}$ & $\begin{array}{l}\text { Parámetro evaluado } \\
\text { de la viremia }\end{array}$ & Principales hallazgos \\
\hline Gubler et $a^{30}$ & Indonesia & $\begin{array}{c}153(42 \mathrm{DC} \\
111 \mathrm{DG})\end{array}$ & $\begin{array}{l}\text { - Duración de la viremia } \\
\text { - Títulos al ingreso y convalecencia }\end{array}$ & No se evidenció relación entre las características de la viremia y la gravedad \\
\hline Vaughn et $a^{25}$ & Tailandia & $\begin{array}{l}168(80 \mathrm{DC} \\
88 \mathrm{DG})\end{array}$ & - Títulos máximos & $\begin{array}{l}\text { Relación directamente proporcional con la gravedad }(r \text { de Pearson }=0.5 \\
p=0,006)\end{array}$ \\
\hline Murgue et $a^{36}$ & $\begin{array}{l}\text { Polinesia } \\
\text { Francesa }\end{array}$ & $\begin{array}{c}49(42 \mathrm{DC} \\
7 \mathrm{DG})\end{array}$ & $\begin{array}{l}\text { - Duración } \\
\text { - Títulos promedio }\end{array}$ & Los pacientes con DG presentaron mayores títulos y duración $(p=0,047)$ \\
\hline Libraty et al ${ }^{24}$ & Tailandia & $\begin{array}{c}54(29 \mathrm{DC} \\
12 \mathrm{DG}, 13 \mathrm{DI})\end{array}$ & $\begin{array}{l}\text { - Títulos a los días } 2,3 \text { y } 4 \\
\text { - Títulos máximos }\end{array}$ & $\begin{array}{l}\text { Las concentraciones durante los días } 3 \text { y } 4 \text { y los máximos fueron significati- } \\
\text { vamente superiores en los pacientes con } D G(p<0,05)\end{array}$ \\
\hline Wang et $a^{26}$ & Taiwán & $\begin{array}{l}20(11 \mathrm{DC} \\
9 \mathrm{DG})\end{array}$ & $\begin{array}{l}\text { - Títulos promedio } \\
\text { - Títulos post-defervescencia }\end{array}$ & $\begin{array}{l}\text { Los títulos promedio y aquellos post-defervescencia fueron superiores en los } \\
\text { pacientes con } D G(p=0,025 \text { y } p=0,008 \text {, respectivamente) }\end{array}$ \\
\hline Chen et al ${ }^{32}$ & Taiwán & $\begin{array}{l}99(66 \mathrm{DC} \\
33 \mathrm{DG})\end{array}$ & $\begin{array}{l}\text { - Títulos promedio } \\
\text { - Títulos en fase febril temprana }\end{array}$ & $\begin{array}{l}\text { No se evidenció diferencia entre los grupos con DC y DG en parámetro } \\
\text { alguno }(p=0,612)\end{array}$ \\
\hline Yeh et $\mathrm{al}^{39}$ & Taiwán & $\begin{array}{l}135(72 \mathrm{DC} \\
63 \mathrm{DG})\end{array}$ & - Títulos según el tipo de infección & $\begin{array}{l}\text { En individuos con infección secundaria se encontró una frecuencia mayor } \\
\text { de } D G(p=0,003) \text {, además de presentar una carga viral significativamente } \\
\text { inferior }(p=0,030)\end{array}$ \\
\hline Wang et $\mathrm{a}^{22}$ & Taiwán & $\begin{array}{l}103 \text { (DC 54, } \\
\text { DG 49) }\end{array}$ & $\begin{array}{l}\text { - Títulos pre- y post-defervescencia } \\
\text { - Duración de la viremia }\end{array}$ & $\begin{array}{l}\text { Los pacientes con } D G \text { presentaron mayores títulos, tanto durante los prime- } \\
\text { ros días de fiebre }(p<0,05) \text {, como al día de defervescencia y los tres poste- } \\
\text { riores a esta }(p<0,001, p<0,001, p=0,001, p=0,03 \text {, respectivamente) } \\
\text { Además, reportaron mayor duración de la viremia comparado con el grupo } \\
\text { de DC (duración promedio, } 7,7 \text { vs. } 6,2 \text { días, respectivamente; } p=0,02)\end{array}$ \\
\hline
\end{tabular}


Tabla 1. Descripción general de los artículos incluidos en la revisión (continuación)

\begin{tabular}{|c|c|c|c|c|}
\hline Autores & País & $\begin{array}{l}\text { Tamaño de } \\
\text { muestra }\end{array}$ & $\begin{array}{l}\text { Parámetro evaluado } \\
\text { de la viremia }\end{array}$ & Principales hallazgos \\
\hline Simmons et a $\left.\right|^{33}$ & Vietnam & 158 & $\begin{array}{l}\text { - Títulos promedio posterior a la } \\
\text { admisión hospitalaria }\end{array}$ & $\begin{array}{l}\text { Se encontró una heterogeneidad importante en los datos de la viremia, } \\
\text { evidenciando que no hay correlación entre los títulos y la gravedad de la } \\
\text { enfermedad }\end{array}$ \\
\hline Silva et $a^{137}$ & Brasil & $\begin{array}{l}85(32 \mathrm{DC} \\
53 \mathrm{DG})\end{array}$ & $\begin{array}{l}\text { - Duración de la viremia } \\
\text { - Títulos máximos }\end{array}$ & $\begin{array}{l}\text { No se encontró relación entre la duración de la viremia o los valores de los } \\
\text { títulos máximos en plasma y las formas clínicas del dengue }(p=0,421)\end{array}$ \\
\hline Guilarde et al ${ }^{38}$ & Brasil & $\begin{array}{l}185(93 \mathrm{DC} \\
49 \mathrm{DI}, 43 \\
\mathrm{DG})\end{array}$ & $\begin{array}{l}\text { - Títulos pre- y post-defervescencia } \\
\text { - Duración de la viremia }\end{array}$ & $\begin{array}{l}\text { No se evidenció correlación entre la magnitud de los títulos y la gravedad } \\
\text { de la enfermedad. La duración de la viremia fue más prolongada en los } \\
\text { casos de DG }\end{array}$ \\
\hline Tang et al43 & China & 285 & $\begin{array}{l}\text { - Niveles de carga viral, IFN } \alpha \text {, IFN } \gamma \text { e } \\
\text { IL-10 }\end{array}$ & $\begin{array}{l}\text { Se encontró una correlación positiva entre la viremia y los niveles de IFN } \alpha \\
(r \text { de Pearson }=0,6446, p<0,0001) \text { y a su vez, una relación negativa } \\
\text { entre las concentraciones de IFN y el recuento plaquetario }(r=-0,2327 \text {, } \\
p<0,0001)\end{array}$ \\
\hline Tricou et al ${ }^{42}$ & Vietnam & $\begin{array}{l}248(179 \\
D C, 69 \mathrm{DG})\end{array}$ & $\begin{array}{l}\text { - Títulos máximos } \\
\text { - Tiempo de aparición de títulos } \\
\text { máximos }\end{array}$ & $\begin{array}{l}\text { No se evidenció diferencia según la gravedad de la enfermedad, tanto en las } \\
\text { concentraciones pico de la viremia como en su momento de presentación } \\
(p>0,05)\end{array}$ \\
\hline Fox et $a^{34}$ & Vietnam & $\begin{array}{l}130(94 \mathrm{DC} \\
36 \mathrm{DG})\end{array}$ & $\begin{array}{l}\text { - Títulos al } 5^{\circ} \text { día de la enfermedad } \\
\text { - Tiempo hasta la desaparición de la } \\
\text { viremia }\end{array}$ & $\begin{array}{l}\text { No se encontró una asociación entre la concentración de ARN viral en plas- } \\
\text { ma y la gravedad de la enfermedad, tanto en el día } 5(p=0,96) \text { como en } \\
\text { el tiempo hasta la desaparición de la viremia }(p=0,85)\end{array}$ \\
\hline Srikiatkhachorn et al ${ }^{29}$ & Tailandia & $\begin{array}{l}35(20 \mathrm{DC} \\
15 \mathrm{DG})\end{array}$ & $\begin{array}{l}\text { - Títulos promedio en plasma } \\
\text { - Niveles de ARN viral al interior de } \\
\text { células mononucleares en sangre } \\
\text { periférica }\end{array}$ & $\begin{array}{l}\text { Se hallaron concentraciones superiores de ARN viral en plasma y al interior } \\
\text { de monocitos en los casos de } D G \text { en comparación con el } D C(p=0,001 \text {; } \\
p=0,01 \text {, respectivamente) }\end{array}$ \\
\hline $\begin{array}{l}\text { de la Cruz-Hernández } \\
\text { et al44 }\end{array}$ & México & $\begin{array}{c}225(120 \\
D C, 105 D G)\end{array}$ & - Títulos promedio & $\begin{array}{l}\text { La carga viral promedio fue superior en los pacientes con DC tanto en sero- } \\
\text { tipo } 1(p=0,0019) \text { como en el } 2(p=0,001)\end{array}$ \\
\hline Pal et $a^{28}$ & India & $\begin{array}{l}108 \text { (78 DC, } \\
30 \text { DSA) }\end{array}$ & - Títulos promedio & $\begin{array}{l}\text { Los pacientes que presentaron signos de alarma presentaron viremias } \\
\text { superiores }\left(2 \times 10^{5} \text { copias } / \mathrm{ml} \text { de diferencia promedio) a comparación de }\right. \\
\text { los que no }\end{array}$ \\
\hline Pozo-Aguilar et al ${ }^{40}$ & México & $\begin{array}{c}220(144 \\
\text { DSA, } 76 \text { DG })\end{array}$ & $\begin{array}{l}\text { - Títulos según el día de la enferme- } \\
\text { dad } \\
\text { - Títulos post-defervescencia }\end{array}$ & $\begin{array}{l}\text { Los pacientes con DSA presentaron títulos de viremia significativamente } \\
\text { superiores tanto en los primeros } 4 \text { días de la enfermedad como en los días } \\
\text { quinto al décimo de la misma }(p<0,0001) \text { y en la post-defervescencia } \\
(p=0,03719)\end{array}$ \\
\hline Singla et $a^{35}$ & India & $\begin{array}{c}97 \text { (21 DC } \\
30 \text { DSA, } 46 \\
\text { DG) }\end{array}$ & $\begin{array}{l}\text { - Títulos promedio } \\
\text { - Títulos post-defervescencia }\end{array}$ & $\begin{array}{l}\text { Se reportó una correlación significativa entre las concentraciones } \\
\text { elevadas de viremia }\left(>10^{7} \text { copias del genoma viral } / \mathrm{ml} \text { en plasma) y la }\right. \\
\text { reducción en los recuentos de plaquetas }(p<0,005) \text {. Sin embargo, no } \\
\text { se correlacionaron con el tipo de infección o directamente la gravedad } \\
\text { de la enfermedad }\end{array}$ \\
\hline Pang et $a^{41}$ & Singapur & $\begin{array}{l}158(82 \mathrm{DC} \\
76 \mathrm{DSA})\end{array}$ & $\begin{array}{l}\text { - Títulos promedio } \\
\text { - Títulos post-defervescencia }\end{array}$ & $\begin{array}{l}\text { En los pacientes hospitalizados se evidenciaron concentraciones superiores } \\
\text { de carga viral }(p<0,001) \text { simultáneas a recuentos inferiores de plaquetas } \\
\text { ( } p<0,001) \text { y linfocitos }(p=0,004) \text { en sangre periférica en los primeros tres } \\
\text { días post-defervescencia. No hubo diferencia entre aquellos que progresaron } \\
\text { a DC y aquellos que no }\end{array}$ \\
\hline
\end{tabular}

*DC: Dengue clásico, DG: Dengue grave, DSA: Dengue con signos de alarma, DI: Dengue forma intermedia entre DC/DG. 
Por otra parte, en la mayoría de estudios se determinó el serotipo causal de la infección, siendo prevalente el serotipo DENV-2 (48,3\%), además de ser el más asociado a gravedad, seguido por el DENV1 (31,6\%), DENV3 $(17,6 \%)$ y finalmente el DENV1 $(2,4 \%)$.

En relación a los desenlaces evaluados, siete artículos estudiaron la duración de la viremia ${ }^{26,30,33,34,36-38}$ 14 la magnitud de la misma ${ }^{24,26,28-30,32,33,35-37,39-41}$, cinco los títulos máximos ${ }^{24,25,32,37,42}$, seis evaluaron los niveles

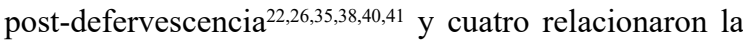
carga viral con indicadores de gravedad como la trombocitopenia, hemoconcentración y fuga de plasma ${ }^{24,29,35,43}$. Por otra parte, a partir de los estudios que la evaluaron se reportó una duración promedio de la viremia de 5,9 días, siendo de 6,2 días en los pacientes con DSA y de 5,8 en aquellos con DC.

Respecto a la correlación entre las características de la viremia y el DG, diez estudios (cinco realizados en población pediátrica) concluyeron que en pacientes con DG o DSA presentaban concentraciones del virus en plasma superiores o una duración más prolongada, llegando a ser detectable hasta varios días posteriores a la defervescencia, en comparación de aquellos con la forma clásica de la enfermedad $22,24-26,28,29,36,38,40,41$. Sumado a esto, un estudio a pesar de descartar una correlación directa con el estatus de DG, asoció los niveles elevados de viremia con marcadores de gravedad como la trombocitopenia ${ }^{35}$. Contrario a esto, dos estudios evidenciaron una correlación negativa entre estas dos variables específicamente tomando los títulos promedio de la viremia, los cuales fueron superiores en los pacientes con $\mathrm{DC}^{39,44}$.

Finalmente, siete estudios descartaron una relación entre las características de la carga viral y la gravedad de la enfermedad. Cabe destacar que seis de estos últimos tuvieron un predominio de casos causados por un serotipo distinto al DENV2, principalmente DENV1 y DENV3, y más aún, dos de estos artículos sólo incluyeron casos con serotipos distintos al DENV2 $2^{32-34,37,42,43,45}$.

\section{Discusión}

La amplia variedad de presentaciones clínicas del dengue representa un reto para el personal de salud en zonas endémicas, pues aún se carece de medios suficientes para la identificación temprana de los pacientes cuya progresión clínica requerirá de intervención posterior ${ }^{46}$. En este contexto, los estudios han dejado ver que múltiples factores, incluyendo el serotipo infectante, la inmunidad del individuo y la carga viral, pueden aportar a la gravedad de la enfermedad; a pesar de esto, la fisiopatología y los factores asociados al desarrollo dengue grave todavía no se comprenden del todo $\mathrm{o}^{41,43,45,47}$. Por su parte, la carga viral ha sido ampliamente estudiada por su posibilidad como factor asociado a gravedad en el contexto de la amplificación dependiente de anticuerpos (ADA), proceso en el cual la presencia de anticuerpos derivados de una infección previa fracasan neutralizando el serotipo de la infección secundaria y llevan, por el contrario, a un incremento en la entrada de las partículas virales al interior de las células del sistema inmune con receptores Fc en su membrana (principalmente macrófagos y monocitos), lo que favorece la replicación del virus y una elevación de sus concentraciones tisulares y en sangre, todo esto asociado a una respuesta inmune más intensa y liberación importante de mediadores vasoactivos ${ }^{48,49}$.

A pesar de esta plausibilidad, aún no existe un consenso acerca de las implicaciones de la viremia en el desarrollo del DG, por lo que la investigación en esta área es activa. Esto se vio reflejado en el número de publicaciones encontradas acerca de este fenómeno, las que en su gran mayoría concuerdan en que la carga viral cumple un papel de importancia en la gravedad del dengue. Sin embargo, los hallazgos varían respecto a la relación establecida, siendo las variables asociadas a formas graves de la enfermedad con mayor evidencia la magnitud de la viremia temprana $^{24,26,36,40}$, el valor de los títulos pico ${ }^{24,25}$ y la duración de la misma posterior a la defervescencia $22,36,38,40,41$. Por una parte, los mayores títulos encontrados en pacientes con DG pueden justificarse por la hipótesis de la ADA, pues múltiples estudios han encontrado asociaciones significativas entre la infección secundaria y la gravedad de la enfermedad ${ }^{25,40,49-52}$. A pesar de esto, se tiene certeza que existen una variedad de factores virales, genéticos e inmunológicos que favorecen el desarrollo de esta condición, por lo que la infección secundaria por sí misma no determina la progresión a $\mathrm{DG}^{45,47,53,54}$.

De manera similar, el hallazgo de persistencia de la viremia posterior a la defervescencia en el DG tiene implicaciones en el estudio de la fisiopatología de la enfermedad. Para explicar este fenómeno se han planteado varias hipótesis; por una parte, se cree que proviene de la liberación residual de ARN viral derivado de un mayor volumen de células infectadas durante el periodo febril. De manera alternativa, se ha postulado que puede deberse a replicación viral persistente durante la defervescencia, pues existe evidencia sobre el aislamiento viral en periodos tardíos de la enfermedad en pacientes con DG por el serotipo $3^{22,26}$. Otra posibilidad evaluada consiste en la diferencia en la efectividad de la eliminación del virus durante la defervescencia en pacientes con la forma grave de la enfermedad y las implicaciones que tienen el tipo de infección, el serotipo infectante y la respuesta de células $\mathrm{T}$ sobre este factor, siendo la eliminación más rápida durante la infección secundaria pero menos eficiente en infecciones por el serotipo 1 del virus y en los casos de disfunción de linfocitos $\mathrm{T}$, en los cuales la apoptosis masiva de clones de células $\mathrm{T}$ específicas para 
el dengue puede aportar a la eliminación más lenta del virus $^{34,42,55-57}$. Relacionado a esto, se ha reportado que en casi la totalidad de pacientes con DG en los que persiste la viremia posterior a la defervescencia, el ARN viral en plasma se encuentra asociado de manera importante a complejos inmunes circulantes, lo que puede jugar un rol de importancia en la fisiopatología de la infección $\operatorname{grave}^{22,23,58,59}$.

Por otra parte, algunos estudios correlacionaron la carga viral con marcadores de gravedad específicos como la trombocitopenia ${ }^{24,37,43}$, hemoconcentración ${ }^{24}$ y fuga de plasma ${ }^{24,29}$. Con respecto al primero, dentro de los potenciales mecanismos de la trombocitopenia asociados al virus se incluyen la trombopoyesis alterada, asociada a la infección de los megacariocitos por el virus llevando a una reducción en sus recuentos y los de sus precursores en la médula ósea ${ }^{60,61}$, y la destrucción periférica de plaquetas, esta última relacionada tanto a la presencia de anticuerpos antiplaquetarios como a la activación de las mismas al interactuar con células endoteliales infectadas por el virus o al ser infectadas por el virus mismo ${ }^{62-64}$. En esta última condición se ha evidenciado que el virus puede provocar disfunción mitocondrial y activación de la cascada de apoptosis de las caspasas por medio de su interacción con la molécula de adhesión DC-SIGN (dendritic cell-specific intercellular adhesion molecule3-grabbing non-integrin) ${ }^{65}$.

A pesar de todo esto, no se encontró unanimidad con respecto a los resultados de los estudios incluidos, pues, pese a que la mayoría concluyó que los niveles de viremia en plasma y su duración se correlacionaron de alguna forma con el grado de gravedad del dengue, hubo otros que no hallaron asociaciones significativas en este sentido ${ }^{30,32-34,37}$.

Estos resultados podrían asociarse al mecanismo de determinación de la viremia ${ }^{30}$, ya que en el aislamiento viral pueden interferir la presencia de anticuerpos o complejos inmunes en plasma, o a la edad de los pacientes evaluados ${ }^{33}$, pues en otras infecciones virales se han evidenciado diferencias en la respuesta inmune del hospedero y las formas clínicas de la enfermedad entre la población pediátrica y adulta ${ }^{66,67}$.

No obstante, debido al origen multifactorial del DG, se podría explicar el desarrollo de esta condición aún con niveles de viremia característicos de los casos de DC. Por tanto, y a pesar de que podrían haber estudios de este tema no considerados por la presente revisión, se puede postular que aunque la cinética y magnitud de la carga viral juegan un papel de importancia en la gravedad de la enfermedad, títulos elevados o prolongados del virus en plasma no resultan indispensables para el desarrollo de DG en un individuo, jugando los factores inmunológicos y genéticos del hospedero junto con las características del virus un rol determinante en estos $\operatorname{casos}^{33,41,43,68,69}$.

Se requieren más estudios en esta área de investigación basados en distintas poblaciones para entender el mecanismo y las condiciones en las cuales la carga viral puede determinar el desarrollo de DG, todo esto contribuyendo al reconocimiento temprano de la gravedad de la enfermedad y al control del fenómeno del dengue en el mundo.

\section{Resumen}

Introducción: La viremia plasmática es un factor cuyo rol en la gravedad de la infección por el virus del dengue se ha discutido ampliamente en los últimos años, siendo hallados resultados divergentes en los múltiples contextos evaluados. Métodos: Se realizó una revisión sistemática de la literatura utilizando las bases de datos Scopus, EBSCOhost, SpringerLink, Lilacs y Scielo. Se consideraron para su inclusión en la revisión estudios que evaluaran la relación entre la carga viral en plasma y las manifestaciones clínicas o la gravedad de la enfermedad. Resultados: Se obtuvieron 80 referencias en la búsqueda inicial, posterior a la aplicación de los criterios de inclusión/exclusión fueron seleccionados 20 artículos. En el estudio de este fenómeno son múltiples los parámetros desde los cuales debe ser evaluada la viremia, no sólo desde su magnitud, sino también desde su duración post-defervescencia y el día en el que se reporta el valor máximo, entre otros. Discusión: Los resultados de los estudios indican que las características de la viremia pueden jugar un rol de importancia que, junto con otros factores del contexto viral (serotipo del virus, tipo de infección) y del paciente (edad, genotipo, comorbilidades, etc), pueden determinar el desenlace clínico de la infección.

\section{Referencias bibliográficas}

1. Bhatt S, Gething P W, Brady O J, Messina J P, Farlow A W, Moyes C L, et al. The global distribution and burden of dengue. Nature. 2013; 496(7446): 504-7. doi: 10.1038/ nature12060. Epub 2013 Apr 7.

2. Raquin V, Wannagat M, Zouache K, Legras-
Lachuer C, Moro CV, Mavingui P. Detection of dengue group viruses by fluorescence in situ hybridization. Parasit Vectors 2012; 5: 243. doi: 10.1186/1756-3305-5-243.

3. Simmons C P, Farrar J J, Nguyen V V C, Wills B. Dengue. N Engl J Med 2012; 366 : 1423-32. doi: 10.1056/NEJMra1110265.

4. WHO Dengue: Guidelines for diagnosis, treatment, prevention and control. Geneva: World Health Organization; 2009. http://www. who.int/tdr/publications/documents/denguediagnosis.pdf.

5. Gubler D J. Epidemic dengue/dengue hemorrhagic fever as a public health, social and economic problem in the 21 st century. Trends Microbiol 2002; 10 (2): 100-3. 
6. Murray N E, Quam M B, Wilder-Smith A. Epidemiology of dengue: past, present and future prospects. Clin Epidemiol. 2013; 5: 299-309. doi: 10.2147/CLEP.S34440.

7. San Martín J L, Brathwaite O, Zambrano B, Solórzano J O, Bouckenooghe A, Dayan G H, et al. The epidemiology of dengue in the americas over the last three decades: a worrisome reality. Am J Trop Med Hyg. 2010; 82(1): 128-35. doi: 10.4269/ ajtmh.2010.09-0346.

8. Ministerio de la Protección Social, Instituto Nacional de Salud. Comportamiento por regiones del dengue en el 2001. Boletín Epidemiológico Semanal, SIVIGILA. Semana epidemiológica No. 02. Enero 06 a 12 de 2002. Disponible en: www.col.ops-oms.org/ sivigila/2002/BOLE02 02.htm

9. Ministerio de la Protección Social, Instituto Nacional de Salud. Comportamiento de los eventos de vigilancia en salud pública. Enfermedades transmitidas por vectores. Boletín Epidemiológico Semanal, SIVIGILA. Semana epidemiológica No. 52.27 dic. 2015 - 22 ene. 2016. Disponible en: http://www. ins.gov.co/boletin-epidemiologico/Boletn $\% 20$ Epidemiolgico/2015\%20Boletin $\% 20$ epidemiologico\%20Semana\%2052.pdf.

10. WHO, Comprehensive Guidelines for Prevention and Control of Dengue and Dengue Haemorrhagic Fever, World Health Organization, 2011, p. 78. http://www.searo. who.int/entity/vector_borne tropical_diseases/ documents/SEAROTPS60/en/

11. Pacheco O, Beltrán M, Nelson C A, Valencia D, Tolosa N, Farr S L, et al. Zika virus disease in Colombia - Preliminary Report. N Engl J Med. 2016. june 15. doi: 10.1056/ NEJMoa1604037

12. Alfaro-Toloza P, Clouet-Huerta D E, Rodríguez-Morales AJ. Chikungunya, the emerging migratory rheumatism. Lancet Infect Dis. 2015 ; 15(5): 510-2. doi: 10.1016/S14733099(15)70160-X. Epub 2015 Apr 19.

13. Lee VJ, Lye DC, Sun Y, Fernandez G, Ong A, Leo YS. Predictive value of simple clinical and laboratory variables for dengue hemorrhagic fever in adults. J Clin Virol 2008; 42: 34-9. doi: 10.1016/j.jcv.2007.12.017. Epub 2008 Feb 20.

14. Leo Y S, Gan V C, Ng E L, Hao Y, Ng L C, Pok K Y, et al. Utility of warning signs in guiding admission and predicting severe disease in adult dengue. BMC Infect Dis 2013; 13: 498. doi: 10.1186/1471-2334-13-498.

15. Soo K M, Khalid B, Ching S M, Chee H Y. Meta-analysis of dengue severity during infection by different dengue virus serotypes in primary and secondary infections. PLoS One. 2016; 11 (5): e0154760. doi: 10.1371/journal. pone. 0154760 .

16. Stephens H A, Klaythong R, Sirikong M, Vaughn D W, Green S, Kalayanarooj S, et al.
HLA-A and -B allele associations with secondary dengue virus infections correlate with disease severity and the infecting viral serotype in ethnic Thais. Tissue Antigens 2002; 60 (4): 309-18.

17. Loke H, Bethell D B, Phuong C X, Dung M, Schneider J, White N J, et al. Strong HLA class I-restricted $\mathrm{T}$ cell responses in dengue hemorrhagic fever: a double-edged sword?. J Infect Dis 2001; 184(11): 1369-73. DOI: $10.1086 / 324320$.

18. Rathakrishnan A, Klekamp B, Wang S M, Komarasamy T V, Natkunam S K, Sathar J, et al. Clinical and immunological markers of dengue progression in a study cohort from a hyperendemic area in Malaysia. PLoS One. 2014; 9(3): e92021. doi: 10.1371/journal. pone.0092021.

19. Bozza F A, Cruz O G, Zagne S M, Azeredo E L, Nogueira R M, Assis E F, et al. Multiplex cytokine profile from dengue patients: MIP1 beta and IFN-gamma as predictive factors for severity. BMC Infect Dis. 2008; 8: 86. doi: 10.1186/1471-2334-8-86.

20. Villar-Centeno L Á, Lozano-Parra A, SalgadoGarcía D, Herrán Ó F. Biochemical alterations as prediction markers for the severity of illness in dengue fever patients. Biomedica 2013; 33 Suppl 1: 63-9.

21. King C A, Marshall J S, Alshurafa H, Anderson R. Release of vasoactive cytokines by antibody-enhanced dengue virus infection of a human mast cell/basophil line. J Virol 2000; 74 (15): 7146-50.

22. Wang W K, Chen H L, Yang C F, Hsieh S C, Juan C C, Chang S M, et al. Slower rates of clearance of viral load and virus-containing immune complexes in patients with dengue hemorrhagic fever. Clin Infect Dis 2006; 43 (8): 1023-30. DOI: $10.1086 / 507635$.

23. Avirutnan P, Punyadee N, Noisakran S, Komoltri C, Thiemmeca S, Auethavornanan $\mathrm{K}$. Vascular leakage in severe dengue virus infections: a potential role for the nonstructural viral protein NS1 and complement. J Infect Dis 2006; 193 (8): 1078-88. DOI: 10.1086/500949.

24. Libraty D H, Endy T P, Houng H S, Green S, Kalayanarooj S, Suntayakorn S, et al. Differing influences of virus burden and immune activation on disease severity in secondary dengue-3 virus infections. J Infect Dis 2002; 185(9): 1213-21. DOI: $10.1086 / 340365$

25. Vaughn D W, Green S, Kalayanarooj S, Innis B L, Nimmannitya S, Suntayakorn S, et al. Dengue viremia titer, antibody response pattern, and virus serotype correlate with disease severity. J Infect Dis 2000; 181(1): 2-9. DOI: $10.1086 / 315215$

26. Wang W K, Chao D Y, Kao C L, Wu H C, Liu Y C, Li C M, et al. High levels of plasma dengue viral load during defervescence in patients with dengue hemorrhagic fever: implications for pathogenesis. Virology 2003; 305 (2): 330-8

27. Endy T P, Nisalak A, Chunsuttitwat S, Vaughn D W, Green S, Ennis F A. Relationship of preexisting dengue virus (DV) neutralizing antibody levels to viremia and severity of disease in a prospective cohort study of DV infection in Thailand. J Infect Dis 2004; 189 (6): 990-1000. DOI: $10.1086 / 382280$

28. Pal T, Dutta S K, Mandal S, Saha B, Tripathi A Differential clinical symptoms among acute phase Indian patients revealed significant association with dengue viral load and serum IFN-gamma level. J Clin Virol 2014; 61(3): 365-70. doi: 10.1016/j.jcv.2014.09.003. Epub 2014 Sep 16.

29. Srikiatkhachorn A, Wichit S, Gibbons R V, Green S, Libraty D H, Endy T P, et al. Dengue viral RNA levels in peripheral blood mononuclear cells are associated with disease severity and preexisting dengue immune status. PLoS One 2012; 7 (12): e51335. https://doi. org/10.1371/journal.pone.

30. Gubler D J, Suharyono W, Tan R, Abidin M, Sie A. Viraemia in patients with naturally acquired dengue infection. Bull World Health Organ 1981; 59: 623-30.

31. Sudiro T M, Zivny J, Ishiko H, Green S, Vaughn D W, Kalayanarooj S, et al. Analysis of plasma viral RNA levels during acute dengue virus infection using quantitative competitor reverse transcription-polymerase chain reaction. J Med Virol 2001; 63 (1): 29-34

32. Chen R F, Liu J W, Yeh W T, Wang L, Chang $\mathrm{J}$ C, Yu H R, et al. Altered T helper 1 reaction but not increase of virus load in patients with dengue hemorrhagic fever. FEMS Immunol Med Microbiol 2005; 44 (1): 43-50. DOI: 10.1016/j.femsim.2004.11.012.

33. Simmons C P, Chau T N, Thuy T T, Tuan N M, Hoang D M, Thien N M, et al. Maternal antibody and viral factors in the pathogenesis of dengue virus in infants. J Infect Dis.2007; 196: 416-24. DOI: 10.1086/519170.

34. Fox A, Le N M, Simmons C P, Wolbers M, Wertheim H F, Pham T K, et al. Immunological and viral determinants of dengue severity in hospitalized adults in Ha Noi, Viet Nam. PLoS Negl Trop Dis 2011; 5 (3): e967. doi: 10.1371/ journal.pntd.0000967.

35. Singla M, Kar M, Sethi T, Kabra SK, Lodha $\mathrm{R}$, Chandele A, et al. Immune response to dengue virus infection in pediatric patients in New Delhi, India-association of viremia, inflammatory mediators and monocytes with disease severity. PLoS Negl Trop Dis 2016; 10 (3): e0004497. doi: 10.1371/journal. pntd.0004497.

36. Murgue B, Roche C, Chungue E, Deparis X Prospective study of the duration and magnitude of viraemia in children hospitalised 
during the 1996-1997 dengue-2 outbreak in French Polynesia. J Med Virol 2000; 60 (4): 432-8.

37. Silva A M. Estudo de cinética de viremia do vírus dengue sorotipo $3 \mathrm{em}$ formas clínicas da dengue com diferentes níveis de gravidade [Tesis]. Recife: Centro de Pesquisas Aggeu Magalhães, Fundação Oswaldo Cruz; 2008. http://www.cpqam.fiocruz.br/bibpdf/2008silvaam.pdf.

38. Guilarde A O, Turchi M D, Siqueira J B Jr, Feres V C, Rocha B, Levi J E, et al. Dengue and dengue hemorrhagic fever among adults: clinical outcomes related to viremia, serotypes, and antibody response. J Infect Dis 2008; 197 (6): 817-24. doi: $10.1086 / 528805$.

39. Yeh W T, Chen R F, Wang L, Liu J W, Shaio M F, Yang K D. Implications of previous subclinical dengue infection but not virus load in dengue hemorrhagic fever. FEMS Immunol Med Microbiol 2006; 48 (1): $84-90$. DOI: $10.1111 / \mathrm{j} .1574-$ 695X.2006.00127.

40. Pozo-Aguilar J O, Monroy-Martínez V, Díaz D, Barrios-Palacios J, Ramos C, Ulloa-García A, et al. Evaluation of host and viral factors associated with severe dengue based on the 2009 WHO classification. Parasit Vectors. 2014; 7: 590. https://doi.org/10.1186/ s13071-014-0590-7.

41. Pang J, Lindblom A, Tolfvenstam $\mathrm{T}$, Thein T L, Naim A N, Ling L, et al. Discovery and validation of prognostic biomarker models to guide triage among adult dengue patients at early infection. PLoS One. 2016; 11(6): e0155993. https://doi.org/10.1371/journal. pone. 0155993

42. Tricou V, Minh N N, Farrar J, Tran H T, Simmons C P. Kinetics of viremia and NS1 antigenemia are shaped by immune status and virus serotype in adults with dengue. PLoS Negl Trop Dis 2011; 5 (9): e1309. https://doi. org/10.1371/journal.pntd.0001309

43. Tang Y, Kou Z, Zhang F, Yao X, Liu S, Ma J, et al. Both viremia and cytokine levels associate with the lack of severe disease in secondary dengue 1 infection among adult Chinese patients. PLoS One 2010; 5 (12): e15631. https://doi.org/10.1371/journal.pone.0015631

44. de la Cruz-Hernández S I, Flores-Aguilar H, González-Mateos S, López-Martinez I, Alpuche-Aranda C, Ludert J E, et al. Determination of viremia and concentration of circulating nonstructural protein 1 in patients infected with dengue virus in Mexico. Am J Trop Med Hyg 2013; 88 (3): 446-54. doi: 10.4269/ajtmh.12-0023.

45. Gubler D J, Suharyono W, Lubis I, Eram S, Gunarso S. Epidemic dengue 3 in central Java, associated with low viremia in man. Am J Trop Med Hyg 1981; 30 (5): 1094-9.

46. Yacoub S, Wills B. Predicting outcome from dengue. BMC Med. 2014 ; 12: 147. https://doi. org/10.1186/s12916-014-0147-9.

47. Pryor M J, Carr J M, Hocking H, Davidson A D, Li P, Wright P J. Replication of dengue virus type 2 in human monocyte-derived macrophages: comparisons of isolates and recombinant viruses with substitutions at amino acid 390 in the envelope glycoprotein. Am J Trop Med Hyg 2001; 65 (5): 427-34.

48. Flipse J, Diosa-Toro M A, Hoornweg T E, van de Pol D P, Urcuqui-Inchima S, Smit J M. Antibody-dependent enhancement of dengue virus infection in primary human macrophages; balancing higher fusion against antiviral responses. Sci Rep 2016; 6: 29201. doi: 10.1038/srep29201.

49. Halstead S B, O'Rourke E J. Antibodyenhanced dengue virus infection in primate leukocytes. Nature 1977; 265: 739-41.

50. Burke D S, Nisalak A, Johnson D E, Scott R M. A prospective study of dengue infections in Bangkok. Am J Trop Med Hyg 1988; 38 (1): 172-80.

51. Guzmán M G, Kouri G P, Bravo J, Soler M, Vazquez S, Morier L. Dengue hemorrhagic fever in Cuba, 1981: a retrospective seroepidemiologic study. Am J Trop Med Hyg 1990; 42 (2): 179-84.

52. Sangkawibha N, Rojanasuphot S, Ahandrik S, Viriyapongse S, Jatanasen S, Salitul V, et al. Risk factors in dengue shock syndrome: a prospective epidemiologic study in Rayong, Thailand. I. The 1980 outbreak. Am J Epidemiol 1984; 120 (5): 653-69.

53. Cologna R, Rico-Hesse R. American genotype structures decrease dengue virus output from human monocytes and dendritic cells. J Virol 2003; 77 (7): 3929-38.

54. Leitmeyer K C, Vaughn D W, Watts D M, Salas R, Villalobos I, de Chacon, et al. Dengue virus structural differences that correlate with pathogenesis. J Virol 1999; 73 (6): 4738-47.

55. Duyen H T, Ngoc T V, Ha do T, Hang V T, Kieu N T, Young P R, et al. Kinetics of plasma viremia and soluble nonstructural protein 1 concentrations in dengue: differential effects according to serotype and immune status. J Infect Dis 2011; 203 (9): 1292-300. doi: 10.1093/infdis/jir014.

56. Klenerman P, Zinkernagel R M. Original antigenic sin impairs cytotoxic $\mathrm{T}$ lymphocyte responses to viruses bearing variant epitopes. Nature 1998; 394: 482-5.

57. Mongkolsapaya J, Dejnirattisai W, Xu X N, Vasanawathana S, Tangthawornchaikul N, Chairunsri A, et al. Original antigenic sin and apoptosis in the pathogenesis of dengue hemorrhagic fever. Nat Med 2003; 9 (7): 921-7. DOI:10.1038/nm887.

58. Patra G, Ghosh M, Modak D, Bandopadhyay B, Saha B, Mukhopadhyay S. Status of circulating immune complexes, IL8 titers and cryoglobulins in patients with dengue infection. Indian J Exp Biol 2015; 53 (11): 719-25.

59. Ruangjirachuporn W, Boonpucknavig S, Nimmanitya S. Circulating immune complexes in serum from patients with dengue haemorrhagic fever. Clin Exp Immunol 1979; 36 (1): 46-53.

60. Noisakran S, Onlamoon N, Hsiao H M, Clark K B, Villinger F, Ansari AA, et al. Infection of bone marrow cells by dengue virus in vivo. Exp Hematol 2012; 40 (3): 250-259.e4. doi: 10.1016/j.exphem.2011.11.011.

61. Sridharan A, Chen Q, Tang K F, Ooi E E, Hibberd M L, Chen J. Inhibition of megakaryocyte development in the bone marrow underlies dengue virus-induced thrombocytopenia in humanized mice. J Virol 2013; 87 (21): 11648-58. doi: 10.1128/ JVI.01156-13.

62. Lin C F, Wan S W, Cheng H J, Lei H Y, Lin Y $\mathrm{S}$. Autoimmune pathogenesis in dengue virus infection. Viral Immunol 2006; 19 (2): 127-32. DOI:10.1089/vim.2006.19.127.

63. Ghosh K, Gangodkar S, Jain P, Shetty S, Ramjee S, Poddar $\mathrm{P}$, et al. Imaging the interaction between dengue 2 virus and human blood platelets using atomic force and electron microscopy. J Electron Microsc 2008; 57: 113 8. doi: 10.1093/jmicro/dfn007

64. Noisakran S, Chokephaibulkit K, Songprakhon P, Onlamoon N, Hsiao HM, Villinger F, et al. A re-evaluation of the mechanisms leading to dengue hemorrhagic fever. Ann N Y Acad Sci 2009; 1171: E24-E35. doi: 10.1111/j.17496632.2009.05050.x.

65. Hottz E D, Oliveira M F, Nunes P C, Nogueira R M, Valls-de-Souza R, Da Poian AT, et al. Dengue induces platelet activation, mitochondrial dysfunction and cell death through mechanisms that involve DC-SIGN and caspases. J Thromb Haemost 2013; 11 (5): 951-62. doi: 10.1111/jth.12178.

66. Baba T W, Jeong Y S, Pennick D, Bronson R, Greene M F, Ruprecht R M. Pathogenicity of live, attenuated SIV after mucosal infection of neonatal macaques. Science 1995; 267 (5205): 1820-5.

67. Falloon J, Eddy J, Wiener L, Pizzo P A. Human immunodeficiency virus infection in children. J Pediatr 1989; 114 (1): 1-30.

68. Clyde K, Kyle J L, Harris E. Recent advances in deciphering viral and host determinants of dengue virus replication and pathogenesis. J Virol 2006; 80 (23): 11418-31. DOI:10.1128/ JVI.01257-06

69. Nguyen T H, Nguyen T L, Lei H Y, Lin Y S, Le B L, Huang K J, et al. Association between sex, nutritional status, severity of dengue hemorrhagic fever, and immune status in infants with dengue hemorrhagic fever. Am J Trop Med Hyg 2005; 72 (4): 370-4. 